\title{
Significance of preoperative left ventricular ejection fraction in 5-year outcome after isolated CABG
}

\author{
Aida Fallahzadeh', Ali Sheikhy' , Ali Ajam², Saeed Sadeghian³, Mina Pashang ${ }^{4}$, Mahmoud Shirzad ${ }^{5}$, \\ Jamshid Bagheri ${ }^{5}$, Soheil Mansourian ${ }^{5}$, Shahram Momtahen ${ }^{5}$ and Kaveh Hosseini ${ }^{3^{*}}$ (D)
}

\begin{abstract}
Background: Pre-operative ejection fraction (EF) and comorbidities affect post-op outcomes. We aimed to compare the mortality and adverse events of patients with different baseline EF and also to evaluate the distribution of comorbidities in each EF group.

Methods: A total of 20,937 patients who underwent isolated coronary artery bypass graft (CABG) surgery from January 2006 to December 2016 was included. Patients were divided into three groups based on their pre-operative left ventricular EF as follows; (1) Normal: EF $\geq 50 \%$; (2) Mild to moderately reduced: 50\% < EF $\leq 35 \%$; and (3) Severely reduced: $\mathrm{EF}<35 \%$. The backward elimination method was considered for multivariate Cox-regression analysis to locate predictors of mortality and non-fatal cerebro-cardiovascular events (CCVEs). The median follow-up time was $5.61[3.12-8.0]$ years.

Results: The mean age in the total population was $60.94 \pm 9.51$ years and $73.6 \%$ of the total population was male. Diabetes mellitus was the common risk factor of mortality and CCVE in all EF groups. Impaired renal function (GFR $<60 \mathrm{ml} / \mathrm{min}$ ) was associated with a higher risk of mortality after CABG regardless of EF level. The median 5-year mortality rate in patients with normal $\mathrm{EF}$, mild-moderately reduced $\mathrm{EF}$ and severely reduced $\mathrm{EF}$ were $9.5 \%, 12.8 \%$, and $22.7 \%$ respectively $(P<0.001)$. Although the trend of CCVEs was higher in severe left ventricle (LV) dysfunction, it was not statistically significant $(p=0.071)$.
\end{abstract}

Conclusion: Patients with severely reduced EF are at higher risk of mortality after CABG compared to those with higher EF levels; however, the rate of CCVEs may not be necessarily higher after adjustment for multiple pre-operative comorbidities.

Keywords: Coronary artery bypass graft (CABG), Left ventricular ejection fraction (LVEF), Mortality

\section{Introduction}

Coronary artery disease (CAD) is the most common type of heart disease and the third leading cause of death in both women and men worldwide [1]. Coronary artery bypass graft $(\mathrm{CABG})$ is the most performed procedure

\footnotetext{
*Correspondence: k-hosseini@tums.ac.ir

${ }^{3}$ Department of Cardiology, Tehran Heart Center, Tehran University of Medical Sciences, North Karegar Ave, PO Box: 1411713138, Tehran, Iran Full list of author information is available at the end of the article
}

in patients with multivessel coronary artery diseases [2]. Indeed, several perioperative risk factors have been reported to affect outcomes after CABG [3].

Traditional predictors of adverse outcomes after CABG are older age, female gender, diabetes mellitus, hypertension, chronic obstructive pulmonary disease (COPD), renal impairment, left main stem disease, and low left ventricular ejection fraction (LVEF) [4]. Therefore, identifying the predictors that may be associated original author(s) and the source, provide a link to the Creative Commons licence, and indicate if changes were made. The images or other third party material in this article are included in the article's Creative Commons licence, unless indicated otherwise in a credit line to the material. If material is not included in the article's Creative Commons licence and your intended use is not permitted by statutory regulation or exceeds the permitted use, you will need to obtain permission directly from the copyright holder. To view a copy of this licence, visit http://creativecommons.org/licenses/by/4.0/. The Creative Commons Public Domain Dedication waiver (http://creativeco mmons.org/publicdomain/zero/1.0/) applies to the data made available in this article, unless otherwise stated in a credit line to the data. 
with worse outcomes after CABG, plays an important role in making a clinical decision and patient selection [5].

Low LVEF is an important predictor of mortality and morbidity after CABG; however, CABG is the treatment of choice in patients with impaired LVEF and is associated with better survival compared to medical therapy alone [6-8]. CABG in such patients is associated with higher postoperative morbidity and mortality compared to those with normal left ventricular function $[9,10]$. However, patients with impaired LVEF have higher preoperative comorbid conditions [11]. Patients with different ejection fraction (EF) levels may have different comorbidities which will affect the postoperative outcomes. Several studies evaluated the inhospital survival and predictors of early outcomes after CABG in patients with low $\operatorname{LVEF}[3,11,12]$; however, few studies focused on comparing the predictors in different EF groups (normal left ventricular [LV] function $>50 \%$, mild to moderate LV dysfunction $35-50 \%$ and severe LV dysfunction $<35 \%$ ) and the mid-term and long-term outcomes. Decreased EF may be related to thromboembolic events through stasis of blood flow, endothelial injury, and hypercoagulability (Virchow triad) [13] and the severity of CAD may be related to the severity of atherosclerotic burden in carotid arteries [14]; thus, the purpose of this study was to identify and compare independent predictors of mortality and cerebro-cardiovascular events (CCVEs) in three preoperative LVEF levels.

\section{Material and method}

\section{Study cohort}

This study is a retrospective registry-based cohort study that was conducted in the clinical registry of Tehran Heart Center (THC) [15]. All data was recorded prospectively at the time of admission. We reported this study according to the Strengthening the Reporting of Observational Studies in Epidemiology (STROBE) statement. This study included patients who underwent CABG surgery from January 2006 to December 2016 and were prospectively followed until 2020. Patients with a lack of sufficient data and those with severe mitral valve regurgitation (MR) (due to overestimation of EF in severe MR) were eliminated from the study. Inclusion criteria were as follows:1) Surgical revascularization criteria for ischemic heart disease and 2) Isolated CABG excluding valve surgeries. Conclusively, 20,937 patients were recruited in the final analysis (Fig. 1). Patients were divided into three groups based on their pre-operative LVEF as follows; (1) $\mathrm{EF} \geq 50 \%$; (2) $50 \%<\mathrm{EF} \leq 35 \%$; and (3) $\mathrm{EF}<35 \%$. The study was approved by the ethical board of THC (IR-THC-13799) and involving human data was under the guidelines of the Declaration of Helsinki. This study didn't meet the criteria for an informed consent form.

\section{Definition of variables}

The following data were included for analysis: Demographic characteristics, graft numbers, comorbidities, preoperative risk factors, and urgency of surgery. Each variable is defined in the Additional file 1.

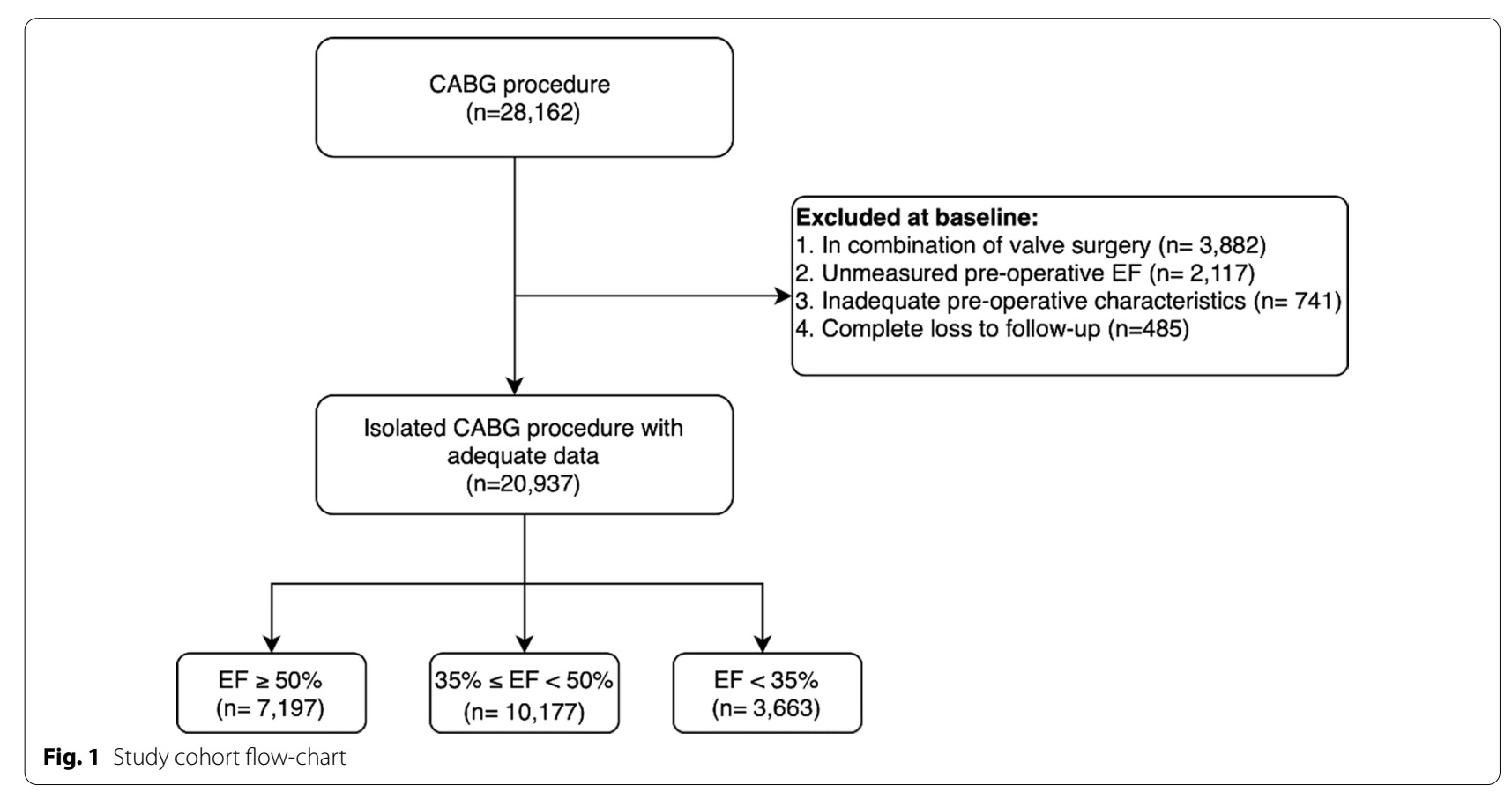




\section{Surgical technique}

Left and right internal mammillary arteries (LIMA and RIMA) and saphenous vein grafts (SVG) were harvested by the "No-touch" technique. In the routine procedure, LIMA was used for the left ascending artery (LAD) and SVG for the right coronary, left circumflex, and diagonal artery, furthermore the grafting conduits selection was based on the surgeon's preference concerning.

For the on-pump CABG procedure, to achieve cardiopulmonary bypass $(\mathrm{CPB})$, a single right atrium and aortic cannulation were made, also, to conserve activated clotting time (ACT) at $\geq 480 \mathrm{~s}$, Heparin was used. Anterograde cold blood cardioplegia was conducted through the surgery. At the end of the surgery, Protamine sulfate was prescribed to neutralize the Heparin. To avoid hypothermia-induced arrhythmia, the patients' systemic temperature was sustained at $36{ }^{\circ} \mathrm{C}$.

For the off-pump CABG procedure, a carbon dioxide blower (Medtronic Inc., Minneapolis, MN) was used for better visualization of the operative field and anastomosis cites. ACT reached $\geq 350$ s by using Heparin. 6-0 monofilament sutures were made for the proximal anastomoses to the aorta, whereas 8-0 monofilament sutures were used for distal anastomosis.

\section{Follow up and study endpoint}

The patients' follow-up protocol was as 4th, 6th, and 12th month of surgery and annually after the last visit through attending visits at the post-op clinics. Telephone interviews were made for individuals who were unable to attend the clinics.

The primary endpoints were mid-term (median 5 years) all-cause mortality and non-fatal CCVEs occurrence (comprising of non-fatal acute coronary syndromes [ACS], non-fatal stroke or transient ischemic attack [TIA], and repeat coronary revascularization via percutaneous coronary intervention $[\mathrm{PCI}]$ or redo-CABG).

\section{Statistical analysis}

Descriptive statistics were used to describe baseline characteristics, subsequently, categorical variables were described as absolute and frequencies, and continuous variables were reported as mean and standard deviation or median and interquartile range according to their distribution. The "Chi-square goodness of fit" was used to compare categorical variables. Normally and nonnormally distributed continuous variables were compared using one-way ANOVA (Analysis of variance) and Kruskal-Wallis test, respectively.

The univariate effect of covariates on mortality and non-fatal CCVEs was assessed by the univariate Cox regression model and reported as hazards ratio (HR) with
95\% confidence intervals. Covariates with $\mathrm{P}$ values less than 0.1 in the univariate Cox regression analyses were entered multivariate Cox-regression analysis. The backward elimination method was considered for multivariate Cox-regression analysis to locate predictors of mortality and non-fatal CCVEs. The Proportional hazard assumption was tested through a graphical assessment based on the scaled Schoenfeld residuals for each final model's variable. Proportional hazard assumption was met for each variable (Additional file 1: Figure S1).

All statistical analyses were conducted applying Stata Statistical Software, release 14 (College Station, TX: StataCorp LP) and R version 4.0.3 [16]. Besides, we used several packages in R: "survival" (package for survival analysis in R) [17], "survminer" (drawing survival curves) [18], and "ggplot2" [19].

\section{Results}

\section{Baseline characteristics}

From January 2006 to December 2016, a total of 20,937 patients who underwent isolated CABG procedures, were included. The median follow-up time was 5.61 [3.12-8.0] years. The mean age in the total population was $60.94 \pm 9.51$ years also, $73.6 \%$ of the total population was male.

In patients with $\mathrm{EF} \geq 50 \%$, the mean of age was $60.75 \pm 9.22$ years and $67.4 \%$ were male, in mild to moderately reduced $\mathrm{EF}$ group $(35 \% \leq \mathrm{EF}<50 \%)$, the mean of age was $60.89 \pm 9.62$ years, and $75.6 \%$ were males. In severely reduced $\mathrm{EF}$ patients $(\mathrm{EF}<35 \%)$, the mean age was $61.05 \pm 9.73$ years and $80.2 \%$ of this group was male. In regard of risk factors, hypertension, dyslipidemia, obesity and family history were higher in normal EF group; while, diabetes mellitus, opium consumption and cigarette smoking were higher in severely reduced EF group. The proportion of performed off-pump surgery was higher in normal EF group (Table 1).

\section{Mid-term outcomes in EF groups All-cause mortality}

Survival probability in patients with severe LV dysfunction $(\mathrm{EF}<35 \%)$ is lower than the other two groups. This trend of lower survival becomes more significant in a longer follow-up duration (Fig. 2). The mortality rate in patients with normal EF, mild-moderately reduced EF and severely reduced EF were 9.5\%, 12.8\%, and $22.7 \%$, respectively.

\section{Non-fatal CCVE}

Although the trend was higher in severe LV dysfunction, it was not significantly different between the three groups in survival analysis $(p=0.071)$ (Fig. 3$)$. In normal $\mathrm{EF}$, mild-moderately reduced $\mathrm{EF}$, and severely reduced $\mathrm{EF}$ 
Table 1 Patients' baseline characteristics based on pre-operative left ventricular ejection fraction

\begin{tabular}{|c|c|c|c|c|}
\hline Ejection fraction (EF) & $E F \geq 50 \%$ & $35 \% \leq \mathrm{EF}<50 \%$ & $\mathrm{EF}<35 \%$ & P value \\
\hline Graft number & $3[3,4]$ & $4[3,4]$ & $4[3,4]$ & $<0.001$ \\
\hline Age (years) & $60.75 \pm 9.22$ & $60.89 \pm 9.62$ & $61.05 \pm 9.73$ & 0.255 \\
\hline \multicolumn{5}{|l|}{ Gender } \\
\hline Female & $2453(32.6 \%)$ & $2544(24.4 \%)$ & $741(19.8 \%)$ & \multirow[t]{2}{*}{$<0.001$} \\
\hline Male & $5073(67.4 \%)$ & 7890 (75.6\%) & $3002(80.2 \%)$ & \\
\hline \multicolumn{5}{|l|}{ eGFR (ml/min) } \\
\hline$\geq 90$ & 2965 (47.3\%) & $3963(44.7 \%)$ & $1233(37.4 \%)$ & \multirow[t]{3}{*}{$<0.001$} \\
\hline $60-89$ & $2412(38.5 \%)$ & 3434 (38.7\%) & $1300(39.5 \%)$ & \\
\hline$<60$ & $891(14.2 \%)$ & $1466(16.5 \%)$ & $761(23.1 \%)$ & \\
\hline Hypertension & $4349(57.8 \%)$ & $5483(52.6 \%)$ & $1778(47.6 \%)$ & $<0.001$ \\
\hline Diabetes mellitus & 2777 (36.9\%) & 4023 (38.6\%) & $1641(43.9 \%)$ & $<0.001$ \\
\hline Dyslipidemia & $4561(60.7 \%)$ & $5678(54.5 \%)$ & $1804(48.3 \%)$ & $<0.001$ \\
\hline Positive Family History & $3124(41.5 \%)$ & 3921 (37.6\%) & $1191(31.8 \%)$ & $<0.001$ \\
\hline Opium & $824(11.2 \%)$ & $1472(14.5 \%)$ & $662(18.3 \%)$ & $<0.001$ \\
\hline Current cigarette smoker & $112515.0 \%$ & $188418.1 \%$ & $77820.9 \%$ & $<0.001$ \\
\hline LM stenosis > 50\% & 669 (8.9\%) & $820(7.9 \%)$ & $364(9.7 \%)$ & 0.001 \\
\hline Pre-Surgery PCI & $438(5.8 \%)$ & $731(7.0 \%)$ & $314(8.4 \%)$ & $<0.001$ \\
\hline Renal failure & $128(1.7 \%)$ & $234(2.3 \%)$ & $131(3.5 \%)$ & $<0.001$ \\
\hline $\mathrm{BMI} \geq 30\left(\mathrm{~kg} / \mathrm{m}^{2}\right)$ & $1968(26.3 \%)$ & $2459(23.6 \%)$ & $696(18.7 \%)$ & $<0.001$ \\
\hline Urgent/Emergent procedure & $250(3.3 \%)$ & 405 (3.9\%) & $139(3.7 \%)$ & 0.139 \\
\hline COPD & $192(2.6 \%)$ & $306(3.0 \%)$ & $144(3.9 \%)$ & 0.001 \\
\hline PVD & $234(3.2 \%)$ & $229(2.2 \%)$ & $72(2.0 \%)$ & 0.124 \\
\hline \multicolumn{5}{|l|}{ Carotid artery stenosis } \\
\hline $20-50 \%$ & $50(0.7 \%)$ & $55(0.5 \%)$ & $13(0.4 \%)$ & \multirow[t]{3}{*}{0.144} \\
\hline $51-75 \%$ & $29(0.4 \%)$ & $35(0.3 \%)$ & $11(0.3 \%)$ & \\
\hline$>75 \%$ & $81(1.1 \%)$ & $93(0.9 \%)$ & $26(0.7 \%)$ & \\
\hline CVA & $388(5.2 \%)$ & $655(6.3 \%)$ & $296(7.9 \%)$ & $<0.001$ \\
\hline \multicolumn{5}{|l|}{ Pre CABG-MI Interval } \\
\hline No Ml & $6136(81.5 \%)$ & $6522(62.5 \%)$ & $1663(44.4 \%)$ & \multirow[t]{4}{*}{$<0.001$} \\
\hline$\leq 7$ Day & $365(4.8 \%)$ & $992(9.5 \%)$ & $415(11.1 \%)$ & \\
\hline 8-21 day & $184(2.4 \%)$ & $622(6.0 \%)$ & 367 (9.8\%) & \\
\hline >21Day & $841(11.2 \%)$ & 2298 (22.0\%) & $1298(34.7 \%)$ & \\
\hline Off-pump surgery & $858(11.9 \%)$ & $741(7.3 \%)$ & $293(8.0 \%)$ & $<0.001$ \\
\hline
\end{tabular}

patients, the non-fatal CCVE rate were as follows; $12.7 \%$, $12.6 \%$, and $12 \%$, respectively.

\section{Estimated HRs for predictors of mid-term outcomes}

All univariate and multivariate cox regression analyses were reported in supplementary data (Additional file 1: Table S1).

\section{All-cause mortality predictors}

Graphical assessment for proportional hazard assumption could be found in supplementary (Additional file 1: Figure S1 and Additional file 1: Fig. S2).
In patients with $E F \geq 50 \%$; age, diabetes mellitus, hypertension, estimated glomerular filtration rate (eGFR) $<60 \mathrm{ml} / \mathrm{min}$, cerebrovascular accident (CVA), peripheral vascular disease (PVD), and carotid artery stenosis $>70 \%$ were significantly related to 5-year mortality.

In patients with mild-moderately reduced EF $(50 \%<\mathrm{EF} \leq 35 \%)$; age, anemia, diabetes mellitus, hypertension, eGFR $<60 \mathrm{ml} / \mathrm{min}, \mathrm{CVA}, \mathrm{COPD}$, left main (LM) stenosis $>50 \%$, PVD, and carotid artery stenosis $>70 \%$ were estimated as risk factors (Table 2).

In patients with severely reduced $\mathrm{EF}(\mathrm{EF}<35 \%)$; COPD and $\mathrm{eGFR}<60 \mathrm{ml} / \mathrm{min}$ were revealed as potential mortality risk factors. 


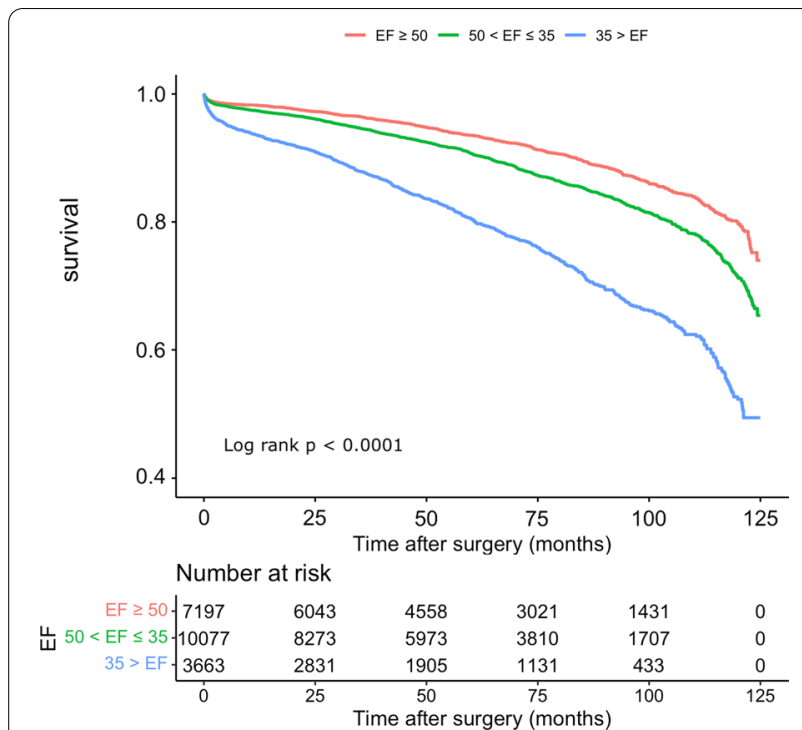

Fig. 2 The Kaplan-Meier survival analysis of patients in three EF groups

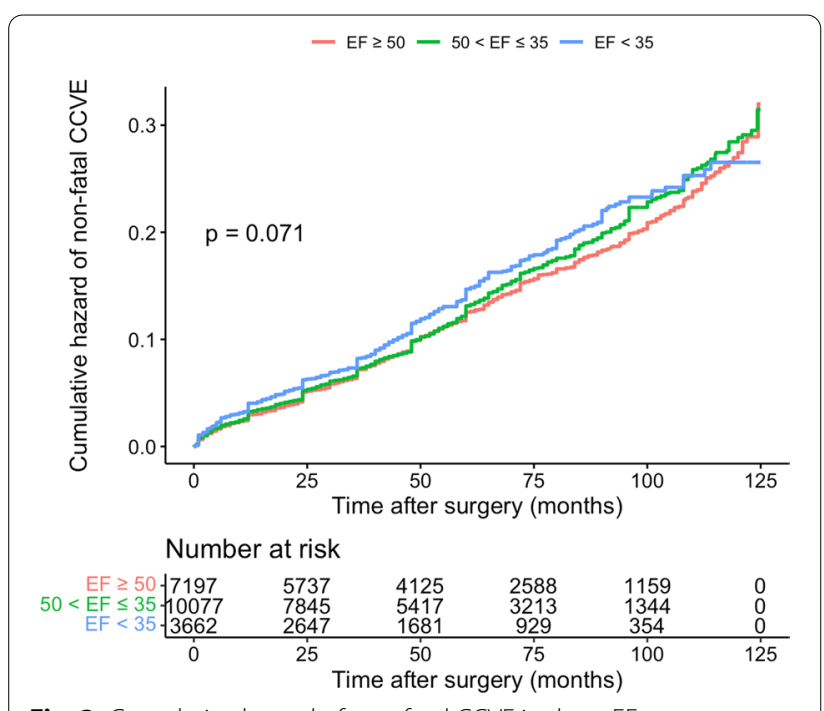

Fig. 3 Cumulative hazard of non-fatal CCVE in three EF groups

\section{Non-fatal CCVEs predictors}

For patients with normal $\mathrm{EF}$ ( $\mathrm{EF} \geq 50 \%$ ); female gender, diabetes mellitus, hypertension, CVA, pre-surgery PCI, and positive family history were shown to be significant.

In mild to moderately reduced $\mathrm{EF}$ patients $(50 \%<\mathrm{EF} \leq 35 \%)$; female gender, diabetes mellitus, hypertension, CVA, cigarette smoking, pre-surgery PCI, and positive family history were associated with a higher risk of non-fatal CCVEs. For severe reduced EF patients ( $\mathrm{EF}<35 \%$ ); diabetes mellitus, and eGFR $<90 \mathrm{ml} / \mathrm{min}$ were related to higher non-fatal CCVEs occurrence (Table 3).

\section{Discussion}

Based on the results of this large sample size registrybased cohort study, distribution of risk factors and predictors of mortality and non-fatal CCVE were not the same in each EF group but had many points in common. Diabetes mellitus is the common risk factor of mortality and CCVE in almost all EF groups. Impaired renal function $(\mathrm{eGFR}<60 \mathrm{ml} / \mathrm{min}$ ) was associated with a higher risk of mortality after CABG regardless of EF level. Older age, diabetes mellitus, history of CVA, and COPD were associated with a higher risk of mortality in the $\mathrm{EF}<50 \%$ group (both mild to moderate and severely reduced groups). Carotid artery stenosis $>70 \%$ was associated with increased risk of mortality in patients with normal and mild to moderate reduced EF.

Although the mortality rate was significantly higher in the severely reduced EF group, this was not statistically significant for non-fatal CCVE. Similar to our findings, Maltais et al. evaluated 1250 patients who underwent off-pump CABG and showed that major adverse cardiac events (MACEs) were not significantly different in patients with $\mathrm{LVEF}<35 \%$ and $\mathrm{LVEF} \geq 35 \%$ after adjustment for potential risk factors [20]. However, another study conducted by El-Shafey et al. evaluated 170 patients who underwent CABG and showed that non-fatal CCVE occurred more significantly in patients with $\mathrm{LVEF}<40 \%$ [21].

Another important and noticeable finding was the role of the female gender in post-CABG outcomes. Although female gender was not significantly associated with higher mortality, it was associated with higher non-fatal CCVE in patients with normal and mild to moderately reduced EF. Similar to our findings, Kurlansky et al. evaluated all patients who underwent coronary revascularization and found that outcomes (MACEs and all-cause mortality) were worse in women who underwent either CABG or PCI [22]. Also, Huckaby et al. evaluated 6163 patients undergoing coronary revascularization and showed that 1-year outcomes (MACE and death) were worse among women with multivessel disease who underwent either CABG or PCI [23]. Besides, a meta-analysis of 20 studies showed that women had an increased risk of short-, mid-, and long-term mortality after isolated CABG compared to men [24]. Another study conducted by Ergunes et al. found that the in-hospital mortality rate was higher in female patients however, the mid-term survival was similar between males and females [25]. However, according to our results, the female gender was not associated with an increased risk of mortality.

Patients with impaired LVEF and CAD have multiple hemodynamic and metabolic abnormalities at rest such as altered myocardial oxygen consumption and lactate metabolism [26]. Therefore, patients with low EF who 
Table 2 Predictors of long-term Mortality: Final step of multivariable cox proportional stepwise regression analysis

\begin{tabular}{|c|c|c|c|}
\hline All-cause mortality & Variable & Multivariate HR $[95 \% \mathrm{Cl}]$ & $P$ value \\
\hline \multirow{8}{*}{$E F \geq 50 \%$} & Age * (years) & $1.047[1.038,1.056]$ & $<0.001$ \\
\hline & Diabetes mellitus & $1.519[1.336,1.727]$ & 0.001 \\
\hline & Hypertension & $1.502[1.281,1.762]$ & $<0.001$ \\
\hline & $\mathrm{eGFR}<60^{\dagger}(\mathrm{ml} / \mathrm{min})$ & $1.390[1.099-1.759]$ & 0.006 \\
\hline & Dyslipidemia & $0.783[0.687,0.893]$ & 0.001 \\
\hline & CVA & $1.467[1.130,1.904]$ & 0.004 \\
\hline & PVD & $1.687[1.215,2.342]$ & 0.002 \\
\hline & Carotid stenosis $>70 \%$ & $2.365[1.472,3.799]$ & $<0.001$ \\
\hline \multirow[t]{13}{*}{$50 \%<\mathrm{EF} \leq 35 \%$} & Age* $^{*}$ (years) & $1.031[1.023,1.038]$ & $<0.001$ \\
\hline & Anemia & $1.323[1.123,1.480]$ & 0.001 \\
\hline & Positive family history & $0.857[0.759,0.967]$ & 0.012 \\
\hline & Diabetes mellitus & $1.429[1.275,1.602]$ & $<0.001$ \\
\hline & Hypertension & $1.372[1.195,1.660]$ & $<0.001$ \\
\hline & $\mathrm{eGFR}<60^{\dagger}(\mathrm{ml} / \mathrm{min})$ & $1.993[1.663,2.388]$ & $<0.001$ \\
\hline & Dyslipidemia & $0.887[0.791,0.995]$ & 0.041 \\
\hline & LM stenosis $>50 \%$ & $1.289[1.123,1.588]$ & 0.015 \\
\hline & CVA & $1.759[1.468,2.108]$ & $<0.001$ \\
\hline & COPD & $2.020[1.606,2.542]$ & $<0.001$ \\
\hline & Off-pump surgery & $0.697[0.564,0.861]$ & 0.001 \\
\hline & PVD & $1.477[1.100,1.981]$ & 0.009 \\
\hline & Carotid stenosis $>70 \%$ & $1.957[1.285,2.979]$ & 0.002 \\
\hline \multirow[t]{3}{*}{$E F<35 \%$} & $\mathrm{eGFR}<60^{\dagger}(\mathrm{m} / \mathrm{min})$ & $1.8251 .399,2.381]$ & $<0.001$ \\
\hline & COPD & $1.436[1.027,2.007]$ & 0.034 \\
\hline & Graft number $^{\ddagger}$ & $0.889[0.807,0.978]$ & 0.016 \\
\hline
\end{tabular}

*HR estimated for increasing 1 year of age

${ }^{\dagger}$ reference: eGFR $>90$

${ }^{\ddagger} \mathrm{HR}$ estimated for increasing $1 \mathrm{graft}$

Table 3 Predictors of non-fatal CCVEs: Final step of multivariable cox proportional stepwise regression analysis

\begin{tabular}{|c|c|c|c|}
\hline Non-fatal CCVEs & Variable & Multivariate HR $[95 \% \mathrm{Cl}]$ & $P$ value \\
\hline \multirow[t]{6}{*}{$E F \geq 50 \%$} & Female & $1.359[1.189,1.554]$ & $<0.001$ \\
\hline & CVA & $1.524[1.181,1.967]$ & 0.001 \\
\hline & Pre-Surgery PCI & $1.611[1.268,2.046]$ & $<0.001$ \\
\hline & Positive Family History & $1.208[1.067,1.369]$ & 0.003 \\
\hline & Hypertension & $1.206[1.055,1.378]$ & 0.006 \\
\hline & Diabetes mellitus & $1.156[1.014,1.318]$ & 0.030 \\
\hline \multirow[t]{7}{*}{$50 \%<\mathrm{EF} \leq 35 \%$} & Female & $1.287[1.135,1.459]$ & $<0.001$ \\
\hline & Pre-Surgery PCl & $1.401[1.146,1.713]$ & 0.001 \\
\hline & Diabetes mellitus & $1.190[1.064,1.331]$ & 0.002 \\
\hline & Hypertension & $1.226[1.096,1.372]$ & $<0.001$ \\
\hline & CVA & $1.513[1.224,1.870]$ & $<0.001$ \\
\hline & Current cigarette smoker & $1.235[1.069,1.427]$ & 0.004 \\
\hline & Positive Family History & $1.233[1.002,1.518]$ & 0.048 \\
\hline \multirow[t]{3}{*}{$E F<35 \%$} & Diabetes mellitus & $1.284[1.106,1.491]$ & $<0.001$ \\
\hline & $60<\mathrm{eGFR}<90^{\dagger}(\mathrm{ml} / \mathrm{min})$ & $1.317[1.045,1.659]$ & 0.020 \\
\hline & $\mathrm{eGFR}<60^{\dagger}(\mathrm{ml} / \mathrm{min})$ & $1.456[1.114,1.904]$ & 0.006 \\
\hline
\end{tabular}

\footnotetext{
${ }^{\dagger}$ Reference: eGFR $>90$ (ml/min)
} 
undergo $C A B G$ are a distinctive group of patients and may have different risk factors associated with postoperative outcomes compared to those with normal EF [3]. Therefore, identification of risk factors associated with adverse outcomes after CABG and selection of patients is important for achieving the optimal postoperative outcome.

According to the surgical treatment for ischemic heart failure extension (STICHES) trial, CABG had clear survival benefits over medical therapy in patients with LVEF $<35 \%$ at 10 -year follow-up [8]. Although CABG is superior to medical therapy in terms of better survival, the outcomes of patients with low LVEF were shown to be worse compared to those with normal EF [10]. Besides the role of net EF value in the post-op outcome, other preoperative predictors also play an important role here. As mentioned before, the distribution and the strength of these predictors are different in each EF group.

Topkara et al. [11] analyzed 55,515 patients who underwent CABG and showed that independent predictors of in-hospital mortality in patients with $\mathrm{EF} \leq 20 \%$ are older age, female gender, renal failure, previous myocardial infarction $(<6 \mathrm{~h})$, and previous open-heart operation. According to our results, older age was the independent predictor of all-cause mortality in patients with $\mathrm{EF}<50$, and female gender was the independent predictor of non-fatal CCVEs in patients with reduced EF $(35 \% \leq \mathrm{EF}<50 \%)$. Shapira et al. [27] evaluated 115 patients with $\mathrm{EF} \leq 30 \%$ who underwent isolated CABG. They found that female gender, renal failure, respiratory complications, and mitral regurgitation are independent predictors of mid-term (36 months) mortality in these patients' groups. Kamal et al. [12] evaluated two propensity-score matched groups $(\mathrm{EF}<50 \%$ and $E F \geq 50 \%$ ) who underwent isolated CABG. They showed that the use of an intra-aortic balloon pump was the independent predictor of early mortality in patients with $E F<50 \%$. Soliman Hamad et al. [3] assessed 413 patients with $\mathrm{EF} \leq 30 \%$ who underwent isolated CABG. They found that age, hemoglobin levels, and creatinine levels are predictors of early mortality after CABG. Vickneson et al. [28] analyzed CABG results of 346 patients with $\mathrm{EF} \leq 30 \%$ and found that hemodynamic instability and kidney dysfunction are independent predictors of 30-day mortality. Similarly, we showed that anemia and eGFR $<60 \mathrm{ml} / \mathrm{min}$ are independent predictors of all-cause mortality in patients with reduced EF $(35 \% \leq \mathrm{EF}<50 \%)$. Khaled et al. [29] evaluated 110 patients with $\mathrm{EF}<50 \%$ who underwent CABG. They showed that diabetes mellitus, diastolic dysfunction, and the use of intra-aortic balloon pumps were predictors of mortality in the study population. Similarly, we found that diabetes mellitus was the independent predictor of all-cause mortality and nonfatal CCVEs in patients with $\mathrm{EF}<50 \%$. Higher rates of adverse outcomes in patients with diabetes mellitus may be due to adverse effects of insulin therapy, inflammatory response, and hormonal overreaction which leads to disruption of cardiovascular function [30]. Gatti et al. [31] conducted a study of 300 patients with $\mathrm{EF} \leq 35 \%$ and showed that poor glycemic control and GFR $<50 \mathrm{ml} / \mathrm{min}$ were independent risk factors for inhospital mortality.

According to our results, dyslipidemia and positive family history were protective factors for all-cause mortality in the reduced EF group. This observation could be partly explained by the utilization of cardiovascular medications such as aspirin, beta-blockers, and statins in patients with a family history of coronary disease [32]. Moreover, they are more likely to exercise, have a healthy diet, be aware of cardiovascular risks, and manage modifiable risk factors such as hypertension [33, 34]. Also, patients with dyslipidemia are more likely to use lipid-lowering medications such as statins. It has been shown that statin therapy is associated with a lower risk of all-cause mortality and MACE after CABG $[35,36]$.

Similarly, Abdi-Ali et al. [32] reported that in patients with proven coronary disease, positive family history was associated with a $23 \%$ relative risk reduction of all-cause mortality over 5.6 years. Two other studies conducted by Canto et al. [37] and Agarwal et al. [38] showed that in a large population of patients with acute myocardial infarction, positive family history is associated with lower inhospital mortality.

\section{Strength and limitation}

The present study should be interpreted in the context of several possible limitations. Our findings were based on midterm follow-up (median 5.61 years), and further studies with longer follow-up are needed to achieve more accurate results. This study was conducted in a single center and the generalizability of our results should be assessed. Still, THC is a referral educational university that serves patients from all over the country. We did not have or permission to have the "autopsy" report of the patients hence the cause of death was unclear.

The major strengths of this study are as follows; First, large sample size presented a considerably high prevalence of events which enhances the power of the study; Second, our data extracted from THC registry data bank which records patient's data prospectively; Third, to overcome surgical expertise limitation, we chose expert surgeons which conducted at least 100 off-pump and 400 on-pump CABG procedures previously. 


\section{Conclusion}

Patients with severely reduced EF are at higher risk of mortality after CABG however the rate of events may not be necessarily higher after adjustment for multiple preoperative comorbidities.

Diabetes mellitus and impaired renal function are important mortality predictors regardless of EF level.

\section{Abbreviations}

EF: Ejection Fraction; PCl: Percutaneous Coronary Intervention; CABG: Coronary Artery Bypass Graft; MACE: Major Adverse Cardiac Event; CCVEs: Cerebro-CardioVascular Events; COPD: Chronic Obstructive Pulmonary Disease; LVEF: Left Ventricular Ejection Fraction; LIMA and RIMA: Left and Right Internal Mammillary Artery; SVG: Saphenous Vein Graft; CPB: CardioPulmonary Bypass; GFR: Glomerular Filtration Rate; ACT: Activated Clotting Timel; ACS: Acute Coronary Syndrome; BMl: Body mass index; Hb: Hemoglobin; eGFR: Estimated glomerular filtration rate; $\mathrm{PCl}$ : Percutaneous coronary intervention; COPD: Chronic obstructive pulmonary disease; CVA: Cerebrovascular accident; MI: Myocardial infarction.

\section{Supplementary Information}

The online version contains supplementary material available at https://doi. org/10.1186/s13019-021-01732-3.

Additional file 1. Table S1: Univariate and multivariate cox regression analyses; Figure S1 and Figure S2: Graphical assessment for proportional hazard assumption.

\section{Acknowledgements}

We acknowledge all healthcare workers involved in the diagnosis and treatment of patients in Tehran Heart Center.

\section{Authors' contributions}

AF, AS and SS: writing the original manuscript. AS: data analysis. MP: acquisition and interpretation of data. AA, MS, JB, SM and SM: revision and preparing the final manuscript. KH: designing of the work. All authors read and approved the final manuscript.

\section{Funding}

None.

\section{Availability of data and materials}

The datasets used and/or analyzed during the current study are available from the corresponding author on reasonable request.

\section{Declarations}

\section{Ethics approval and consent to participate}

The study was approved by the ethical board of THC (IR-THC-13799) and involving human data was under the guidelines of the Declaration of Helsinki. This study didn't meet the criteria for an informed consent form.

\section{Consent for publication}

Not applicable.

\section{Competing interests}

The authors declare that they have no competing interests.

\section{Author details}

${ }^{1}$ Research Department, Tehran Heart Center, Tehran University of Medical Sciences, Tehran, Iran. '2 Students' Scientific Research Center (SSRC), Tehran University of Medical Sciences, Tehran, Iran. ${ }^{3}$ Department of Cardiology, Tehran Heart Center, Tehran University of Medical Sciences, North Karegar Ave, PO Box: 1411713138, Tehran, Iran. ${ }^{4}$ Tehran Heart Center, Tehran University of Medical
Sciences, Tehran, Iran. ${ }^{5}$ Department of Surgery, Tehran Heart Center, Tehran University of Medical Sciences, Tehran, Iran.

Received: 26 July 2021 Accepted: 24 November 2021

Published online: 27 December 2021

\section{References}

1. Brown JC, Gerhardt TE, Kwon E. risk factors for coronary artery disease. StatPearls. Treasure Island (FL): StatPearls Publishing Copyright (c) 2021, StatPearls Publishing LLC.; 2021.

2. Spadaccio $C$, Benedetto U. Coronary artery bypass grafting (CABG) vs. percutaneous coronary intervention (PCI) in the treatment of multivessel coronary disease: quo vadis? A review of the evidences on coronary artery disease. Ann Cardiothoracic Surg. 2018;7(4):506-15.

3. Soliman Hamad MA, van Straten AH, van Zundert AA, ter Woorst JF, Martens EJ, Penn OC. Preoperative prediction of early mortality in patients with low ejection fraction undergoing coronary artery bypass grafting. J Card Surg. 2011;26(1):9-15.

4. Kamal YA A-ES, Ghoneim A, El-Minshawy A. Traditional predictors of in-hospital mortality after coronary artery bypass grafting: current status. 2017

5. Heijmans JH, Maessen JG, Roekaerts PM. Risk stratification for adverse outcome in cardiac surgery. Eur J Anaesthesiol. 2003;20(7):515-27.

6. Alderman EL, Fisher LD, Litwin P, Kaiser GC, Myers WO, Maynard C, et al. Results of coronary artery surgery in patients with poor left ventricular function (CASS). Circulation. 1983;68(4):785-95.

7. Passamani E, Davis KB, Gillespie MJ, Killip T. A randomized trial of coronary artery bypass surgery. Survival of patients with a low ejection fraction. N Engl J Med. 1985;312(26):1665-71.

8. Velazquez EJ, Lee KL, Jones RH, Al-Khalidi HR, Hill JA, Panza JA, et al. Coronary-artery bypass surgery in patients with ischemic cardiomyopathy. N Engl J Med. 2016;374(16):1511-20.

9. Zubiate $\mathrm{P}$, Kay JH, Mendez AM. Myocardial revascularization for the patient with drastic impairment of function of the left ventricle. J Thorac Cardiovasc Surg. 1977;73(1):84-6.

10. Christakis GT, Weisel RD, Fremes SE, Ivanov J, David TE, Goldman BS, et al. Coronary artery bypass grafting in patients with poor ventricular function. J Thorac Cardiovasc Surg. 1992;103(6):1083-92.

11. Topkara VK, Cheema FH, Kesavaramanujam S, Mercando ML, Cheema AF, Namerow PB, et al. Coronary artery bypass grafting in patients with low ejection fraction. Circulation. 2005;112(9_supplement):I-344-I-50.

12. Kamal YA, Al-Elwany SEM, Ghoneim AMF, El-Minshawy AMK. Predictors of adverse effects after coronary artery bypass grafting in patients with reduced left ventricular ejection fraction. J Egypt Soc Cardio-Thoracic Surg. 2017;25(1):20-7

13. Lip GY, Gibbs CR. Does heart failure confer a hypercoagulable state? Virchow's triad revisited. J Am Coll Cardiol. 1999;33(5):1424-6.

14. Bytyçi I, Shenouda R, Wester P, Henein MY. Carotid atherosclerosis in predicting coronary artery disease. Arterioscler Thromb Vasc Biol. 2021;41(4):e224-37

15. Poorhosseini H, Abbasi SH. The Tehran Heart Center. Eur Heart J. 2018;39(29):2695-6.

16. R Core Team (2020). R: A language and environment for statistical computing. R Foundation for Statistical Computing, Vienna, Austria. 2020.

17. (2021). TT. A Package for Survival Analysis in R.. R package version 3.2-10. 2021.

18. Alboukadel Kassambara MKaPB. survminer: Drawing Survival Curves using 'ggplot2'. R package version 0.4.9. 2021.

19. Wickham H. ggplot2: Elegant Graphics for Data Analysis. New York: Springer; 2016

20. Maltais S, Ladouceur M, Cartier R. The influence of a low ejection fraction on long-term survival in systematic off-pump coronary artery bypass surgery . Eur J Cardiothorac Surg. 2011;39(5):e122-7.

21. El-Shafey W, Elnagar T, Kamal A, Kamal A. Early results of coronary artery bypass graft (CABG) in patients with low ejection fraction. World J Cardiovasc Dis. 2020;10:319-28.

22. Kurlansky P, Herbert M, Prince S, Mack M. Coronary bypass versus percutaneous intervention: sex matters. The impact of gender on long-term 
outcomes of coronary revascularization. Eur J Cardio-Thoracic Surg. 2017:51(3):554-61.

23. Huckaby LV, Seese LM, Sultan I, Gleason TG, Wang Y, Thoma F, et al. The impact of sex on outcomes after revascularization for multivessel coronary disease. Ann Thorac Surg. 2020;110(4):1243-50.

24. Alam M, Bandeali SJ, Kayani WT, Ahmad W, Shahzad SA, Jneid H, et al. Comparison by meta-analysis of mortality after isolated coronary artery bypass grafting in women versus men. Am J Cardiol. 2013;112(3):309-17.

25. Erguneș K, Yilik L, Yetkin U, Lafcı B, Bayrak S, Ozpak B, et al. Early and midterm outcomes in female patients undergoing isolated conventional coronary surgery. J Cardiovasc Thorac Res. 2014;6(2):105-10.

26. De Marco T, Chatterjee K, Rouleau JL, Parmley WW. Abnormal coronary hemodynamics and myocardial energetics in patients with chronic heart failure caused by ischemic heart disease and dilated cardiomyopathy. Am Heart J. 1988;115(4):809-15.

27. Shapira OM, Hunter CT, Anter E, Bao Y, DeAndrade K, Lazar HL, et al. Coronary artery bypass grafting in patients with severe left ventricular dysfunction-early and mid-term outcomes. J Card Surg. 2006;21 (3):225-32.

28. Vickneson K, Chan SP, LiY, Bin Abdul Aziz MN, Luo HD, Kang GS, et al. Coronary artery bypass grafting in patients with low ejection fraction: what are the risk factors? J Cardiovasc Surg. 2019;60(3):396-405.

29. Khaled S, Kasem E, Fadel A, alzahrani Y, Banjar K, Al-Zahrani Wa, et al. Left ventricular function outcome after coronary artery bypass grafting, King Abdullah Medical City (KAMC)- single-center experience. Egypt Heart J. 2019;71(1):2.

30. Dangas GD, Farkouh ME, Sleeper LA, Yang M, Schoos MM, Macaya C, et al. Long-term outcome of $\mathrm{PCl}$ versus $\mathrm{CABG}$ in insulin and non-insulintreated diabetic patients: results from the FREEDOM Trial. J Am Coll Cardiol. 2014;64(12):1189-97.

31. Gatti G, Maschietto L, Dell'Angela L, Benussi B, Forti G, Dreas L, et al. Predictors of immediate and long-term outcomes of coronary bypass surgery in patients with left ventricular dysfunction. Heart Vessels. 2016;31(7):1045-55.

32. Abdi-Ali A, Shaheen A, Southern D, Zhang M, Knudtson M, White J, et al. Relation between family history of premature coronary artery disease and the risk of death in patients with coronary artery disease. Am J Cardiol. 2015;117.

33. Chow CK, Islam S, Bautista L, Rumboldt Z, Yusufali A, Xie C, et al. Parental history and myocardial infarction risk across the world: the INTERHEART Study. J Am Coll Cardiol. 2011;57(5):619-27.

34. Williamson C, Jeemon P, Hastie CE, McCallum L, Muir S, Dawson J, et al. Family history of premature cardiovascular disease: blood pressure control and long-term mortality outcomes in hypertensive patients. Eur Heart J. 2014;35(9):563-70.

35. Kulik A, Brookhart MA, Levin R, Ruel M, Solomon DH, Choudhry NK. Impact of statin use on outcomes after coronary artery bypass graft surgery. Circulation. 2008;118(18):1785-92.

36. Philip F, Blackstone E, Kapadia SR. Impact of statins and beta-blocker therapy on mortality after coronary artery bypass graft surgery. Cardiovasc Diagn Ther. 2015;5(1):8-16.

37. Canto JG, Kiefe Cl, Rogers WJ, Peterson ED, Frederick PD, French WJ, et al. Atherosclerotic risk factors and their association with hospital mortality among patients with first myocardial infarction (from the National Registry of Myocardial Infarction). Am J Cardiol. 2012;110(9):1256-61.

38. Agarwal MA, Garg L, Lavie CJ, Reed GL, Khouzam RN. Impact of family history of coronary Artery disease on in-hospital clinical outcomes in STsegment myocardial infarction. Ann Transl Med. 2018;6(1):3.

\section{Publisher's Note}

Springer Nature remains neutral with regard to jurisdictional claims in published maps and institutional affiliations. 